\title{
Prognostic Value of Exercise Stress Echocardiography in Patients with Left Bundle Branch Block
}

\author{
Francis de Lima Vasconcelos' ${ }^{1}$ Bruno Fernandes de Oliveira Santos ${ }^{1}$, Nathalie de Oliveira Santana', Gustavo \\ Baptista de Almeida Faro', Romerito de Oliveira Rocha' , Vinício Vieira Leal'1, José Augusto Barreto-Filho',2, \\ Antônio Carlos Sobral Sousa ${ }^{1,2}$, Joselina Luzia Menezes Oliveira ${ }^{1,2}$ \\ Departamento de Medicina - Universidade Federal de Sergipe ${ }^{1}$ - São Cristovão, SE; Laboratório de Ecocardiografia (ECOLAB) do Hospital e \\ Fundação São Lucas² - Aracaju, SE, Brazil
}

\begin{abstract}
Background: The literature lacks studies about the prognostic value of exercise stress echocardiography (ESE) in patients with complete left bundle branch block (LBBB) of the bundle of His.
\end{abstract}

Objective: To assess the prognostic value of ESE in patients with LBBB.

Methods: This is a retrospective cohort that evaluated 135 patients with LBBB, from January 2001 to October 2009, of which $37.8 \%$ were men, mean age $63.6 \pm 11.5$ years submitted to ESE according to Bruce protocol on a treadmill. Cox regression was used, considering these outcomes: death from all causes and from cardiac events, defined as acute myocardial infarction (AMI), percutaneous angioplasty (PA), coronary artery bypass grafting (CABG) and death from cardiac causes.

Results: Positive ESE was observed in 42 patients (31\%). The mean follow-up was $45.8 \pm 4.7$ months. During this period, there were 9 deaths from all causes and 9 cardiac events ( 3 deaths from cardiac causes, 3 myocardial infarctions, 2 PA and one CABG). The mortality rate from all causes during five years was $16.1 \%$ in the group with positive ESE and $2.5 \%$ in the group with negative test $(p=0.171)$, whereas the rate of cardiac events in the same period was $15.1 \%$ for the positive ESE and $1.6 \%$ in the group with negative test $(p=0.009)$.

Conclusion: ESE showed to be a predictor of cardiac events in patients with LBBB. (Arq Bras Cardiol 2011;97(6):478-484)

Keywords: Echocardiography, stress; bundle-branch block; prognosis; coronary artery disease.

\section{Introduction}

The left bundle branch block (LBBB) of the bundle of His is easily detected by the electrocardiogram (ECG). It may be associated with progressive disorder of the conduction system or occur in patients with no evidence of heart disease. LBBB interferes with the interpretation of the exercise test, in addition to inducing ventricular dyssynchrony, thus impairing the evaluation of left ventricular function. According to epidemiological studies carried out in the last thirty years, the prevalence of the LBBB has varied between 0.1 and $0.8 \%$ in the U.S. population ${ }^{1-5}$.

Approximately one third of patients with heart failure have a conduction disorder and LBBB is the one most often found $(25 \%)^{6}$. It is associated with increased cardiovascular morbimortality and may be considered a marker of a slowly and progressive cardiac degeneration of ischemic or nonischemic causes ${ }^{7}$.

Mailing Address: Joselina Luzia Menezes Oliveira •

Praça Graccho Cardoso, 76/402, São José - 49015-180 - Aracaju, SE, Brazil E-mail: jlobelem@cardiol.br, joselinasergipe@ig.com.br Manuscript received March 08, 2011; revised manuscript received May 30, 2011; accepted June 22, 2011.
Exercise stress echocardiography (ESE) is a noninvasive method of great value for the diagnosis and risk stratification of coronary artery disease (CAD) ${ }^{8-11}$. This technique allows the analysis of left ventricular function at rest and under stress, as well as the detection of the presence, location and extent of alterations in wall motion in response to stress. It also has high availability and reliability, in addition to being low cost and eliminating the need for radioactive material use $\mathrm{e}^{12}$. The ESE is also able to detect ischemic changes earlier than the exercise test (ET), as previously demonstrated by several studies ${ }^{13}$.

Therefore, this is an established and versatile tool for the diagnosis and risk stratification of CAD in the general population. However, its applicability in patients with LBBB is not yet well established. Considering that, the present study aims to evaluate the prognostic value of ESE in patients with LBBB.

\section{Methods}

\section{Patients}

Between January 2001 and October 2009, a total of 6,731 patients underwent exercise stress echocardiography at the 
Laboratory of Echocardiography of Clínica e Hospital São Lucas (ECOLAB), Aracaju-SE. In this sample, we identified 243 patients with LBBB. During follow-up, 108 patients were excluded from the study, as it was not possible to follow them by telephone contact. We also excluded those who refused to participate in the study, those with poor-quality imaging tests and those with significant valvular heart disease.

LBBB was defined as wide QRS complex (duration $\geq 120 \mathrm{~ms}$ ), with predominantly positive QRS complexes, and wide $\mathrm{R}$ waves in leads DI, V5 and V6 and rS or QS patterns in $\mathrm{V}^{4}{ }^{4}$.

\section{Test protocol}

The test was initiated with the medical history, physical examination, blood pressure and heart rate measurement, 12-lead electrocardiogram and echocardiography at rest. Subsequently, the ET was performed according to the Bruce protocol.

The echocardiographic images were obtained at rest, immediately after the physical exertion and during the recovery period, using two-dimensional echocardiography, pulsed Doppler and tissue Doppler. The echocardiographic variables were obtained and measured according to the recommendations of the American Society of Echocardiography ${ }^{12}$. The two-dimensional echocardiographic images were recorded on video home system (VHS) tapes and digital video discs (DVDs), with the patient on left lateral decubitus and simultaneous electrocardiographic recording in the parasternal acoustic windows (longitudinal and transverse) and apical (two-chamber and four-chamber).

\section{ESE Analysis}

The images obtained at the three moments of the examination were placed side by side in quad screen format and were analyzed and compared at different heart rates by an experienced level-III echocardiographist, according to criteria established by the American Society of Echocardiography. This organization also recommends that the left ventricle (LV) should be assessed by standard echocardiographic planes, defining 16 segments, and that the examinations should be recorded for later review. Scores were given to each of the 16 segments: 1 - normal segments, 2 - segments with decreased thickness (hypokinetic), 3 - segments without thickening (akinetic) and 4 - segments with dyskinetic movements. The left ventricular wall motion index (LVWMI) was obtained by adding the scores given to each of the 16 segments divided by the number of studied segments. This evaluation was performed at rest and after exercise stress ${ }^{11,14}$.

The test was considered positive if segmental contractility abnormalities occurred in the myocardium at rest and / or after exercise. Ischemia was defined as the onset or worsening of segmental contractility abnormalities in the myocardium after exercise ${ }^{15}$.

\section{Follow-up}

Follow-up was carried out through telephone interviews. The outcomes analyzed were deaths from all causes and occurrence of the first major cardiac event (acute myocardial infarction (AMI), percutaneous coronary intervention $(\mathrm{PCl})$, coronary artery bypass grafting $(\mathrm{CABG})$ or death from cardiac causes).

\section{Statistical Analysis}

Categorical variables were described as number of cases and percentages, and comparisons between groups were carried out by Chi-square $\left(\chi^{2}\right)$ or Fisher exact test. Quantitative variables were characterized as mean \pm standard deviation, and comparisons between groups were carried out using unpaired $t$ test. The cumulative event curves were estimated by the Kaplan-Meier method and compared by log-rank test. Cox regression was used to assess risk factors for cardiac events and overall mortality and $\mathrm{p}$ values $<0.05$ were considered significant. Statistical analysis was carried out with SPSS software, release 17.0 (SPSS Inc., Chicago, Illinois).

\section{Ethical Aspects}

The Ethics Committee of the Federal University of Sergipe was requested an extension for the research project "Chronotropic Incompetence Adds Positive Predictive Value to Obstructive Coronary Disease at Exercise Stress Echocardiography", previously approved under Protocol \#1818.0.000.107-06. All patients signed the free informed consent form.

\section{Results}

\section{Clinical characteristics of the studied population}

Of the 135 patients, 51 (37.8\%) were men. The mean age was $63.6 \pm 11.6$, ranging from 36 to 89 years. The patients were divided in two groups according to the ESE result: Negative ESE ( $n=93,69.9 \%$ ) and positive ESE ( $n=42$, $31.1 \%$ ). The majority of patients with positive ESE was male and had a history of myocardial infarction (Table 1).

\section{Clinical Hemodynamic and Echocardiographic Parameters}

There were no complications during the examinations. Of the 135 patients submitted to ESE, 42 (31.1\%) had a positive test. However, of these patients, 18 (42.9\%) had altered motility only at rest, 17 (40.5\%) had no motility alterations at rest and developed ischemia during the examination, and seven $(16.7 \%)$ had motility alterations at rest and developed ischemia during the examination (Table 2).

\section{Follow-up}

The mean follow-up was $45.8 \pm 4.7$ months. During this period, there were nine cardiac events (three AMI, one CABG, two PA and three deaths from cardiac causes) and eight deaths (in addition to the three from cardiac causes, two deaths due to cerebrovascular accident, one due to gastric neoplasm, one due to pneumonia and one due to pulmonary emphysema). The five-year mortality rate was $16.1 \%$ for the group with a positive test and $2.5 \%$ in the group with a negative test $(p=$ 0.171 ) (Figure 1), whereas the rate of cardiac events during the same period was $15.1 \%$ in the group with a positive test and $1.6 \%$ in the group with a negative test $(p=0.009)$ (Figure 2$)$. 


\section{Original Article}

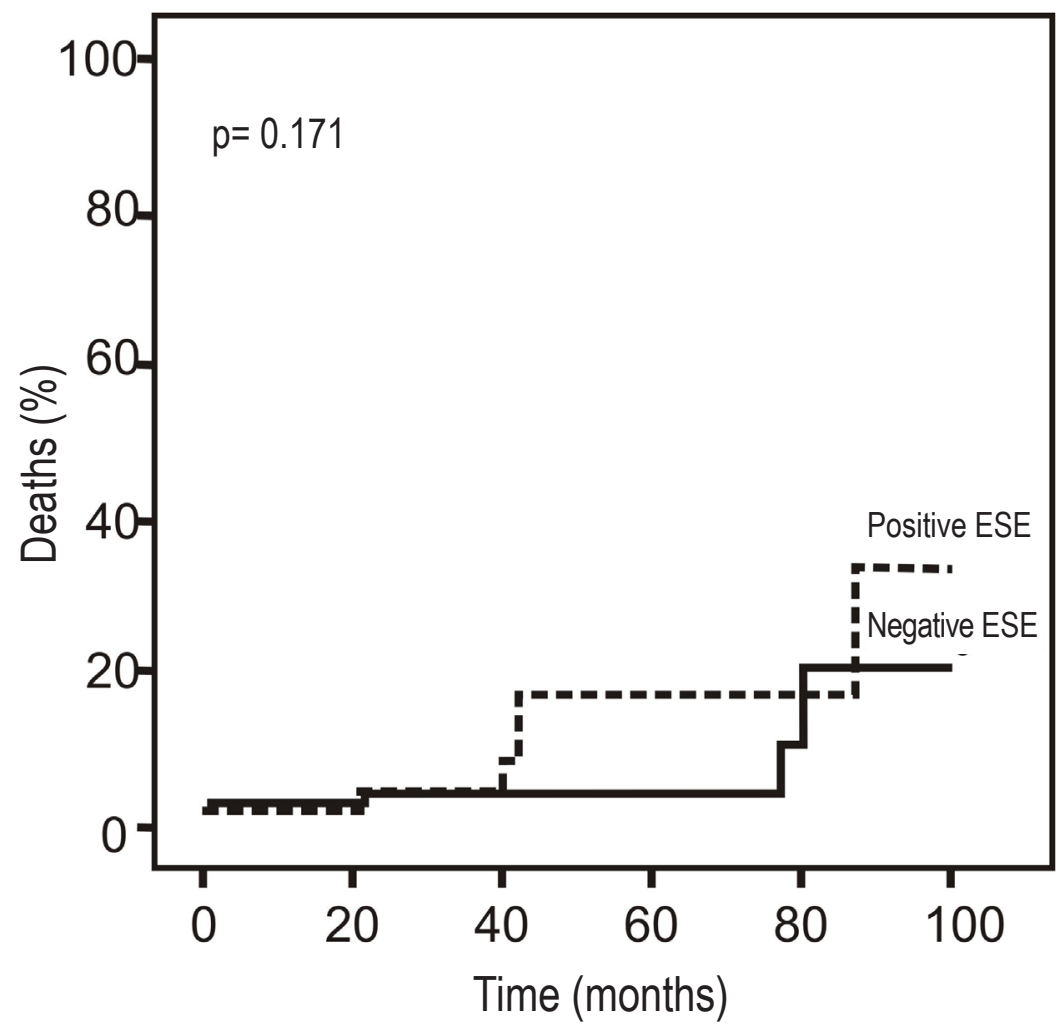

Figure 1 - Kaplan-Meier curve showing the cumulative incidence of deaths in LBBB patients with positive and negative ESE.

Table 1 - Clinical findings in LBBB patients with positive and negative ESE

\begin{tabular}{|c|c|c|c|c|}
\hline & $\begin{array}{c}\text { All patients } \\
(\mathrm{n}=135)\end{array}$ & $\begin{array}{c}\text { Negative } \\
\text { ESE }(n=93)\end{array}$ & $\begin{array}{l}\text { Positive ESE } \\
(n=42)\end{array}$ & $\mathrm{p}$ \\
\hline Men, $\mathrm{n}(\%)$ & $51(37.8 \%)$ & $27(29 \%)$ & $24(57.1 \%)$ & 0.002 \\
\hline Age, years & $63.6 \pm 11.6$ & $62.2 \pm 11.8$ & $66.9 \pm 10.5$ & 0.286 \\
\hline Smoking, n (\%) & $3(2.3 \%)$ & $2(2.2 \%)$ & $1(2.5 \%)$ & 0.915 \\
\hline DM, n (\%) & $15(11.5 \%)$ & $11(12.1 \%)$ & $4(10 \%)$ & 0.730 \\
\hline $\mathrm{BMI}, \mathrm{kg} / \mathrm{m}^{2}$ & $27.1 \pm 4.3$ & $26.9 \pm 4.3$ & $27.6 \pm 4.5$ & 0.803 \\
\hline Obesity, n (\%) & $33(24.4 \%)$ & $23(24.7 \%)$ & $10(23.8 \%)$ & 0.908 \\
\hline Sedentary lifestyle, $n(\%)$ & $33(56.9 \%)$ & $22(51.2 \%)$ & $11(73.3)$ & 0.135 \\
\hline Alcohol consumption, $n(\%)$ & $17(28.8 \%)$ & $11(25 \%)$ & $6(40 \%)$ & 0.282 \\
\hline Hypertension, n (\%) & $84(64.1 \%)$ & $55(60.4 \%)$ & $29(72.5 \%)$ & 0.185 \\
\hline Dyslipidemia, n (\%) & $86(65.6 \%)$ & $57(62.6 \%)$ & $29(72.5 \%)$ & 0.274 \\
\hline $\mathrm{FH}$ of $\mathrm{CAD}, \mathrm{n}(\%)$ & $74(56.5 \%)$ & $47(51.6 \%)$ & $27(67.5 \%)$ & 0.092 \\
\hline Previous CAD, n (\%) & $7(5.5 \%)$ & $1(1.1 \%)$ & $6(15.4 \%)$ & 0.001 \\
\hline CABG, $n(\%)$ & $9(7.1 \%)$ & $2(2.3 \%)$ & $7(17.9 \%)$ & 0.001 \\
\hline
\end{tabular}

ESE - exercise stress echocardiography; DM - diabetes mellitus; BMI - body mass index; FH - family history; CAD - coronary artery disease; CABG - coronary artery bypass graft. 
Table 2 - Clinical, hemodynamic and echocardiographic parameters during ESE in patients with LBBB

\begin{tabular}{|c|c|c|c|c|}
\hline & $\begin{array}{l}\text { All patients } \\
(n=135)\end{array}$ & Negative ESE $(n=93)$ & Positive ESE $(n=42)$ & $p$ \\
\hline SBP at rest, $\mathrm{mmHg}$ & $132.4 \pm 14.9$ & $131.1 \pm 14.5$ & $135 \pm 15.5$ & 0.572 \\
\hline Peak SBP, mmHg & $185.9 \pm 19.9$ & $186.5 \pm 19.1$ & $184.6 \pm 21.8$ & 0.286 \\
\hline DBP at rest, $\mathrm{mmHg}$ & $82.1 \pm 8.1$ & $82.4 \pm 8.7$ & $81.3 \pm 6.6$ & 0.057 \\
\hline Peak DBP, mmHg & $85.1 \pm 9$ & $85.5 \pm 9.3$ & $84.4 \pm 8.3$ & 0.344 \\
\hline $\mathrm{HR}$ at rest, beats/min & $78.4 \pm 17$ & $78 \pm 15.4$ & $79.2 \pm 20.4$ & 0.308 \\
\hline Peak HR, beats/min & $146.4 \pm 20.4$ & $148.8 \pm 19.7$ & $141.1 \pm 21$ & 0.623 \\
\hline Precordial pain, $n(\%)$ & $7(5.2 \%)$ & 0 & $7(16.7 \%)$ & $<0.001$ \\
\hline Peak hypertension, n (\%) & $18(13.3 \%)$ & $14(15.1 \%)$ & $4(9.5 \%)$ & 0.382 \\
\hline Dyspnea, n (\%) & $20(14.8 \%)$ & $8(8.6 \%)$ & $12(28.6 \%)$ & 0.002 \\
\hline $\mathrm{Cl}, \mathrm{n}(\%)$ & $51(37.8 \%)$ & $34(36.6 \%)$ & $17(40.5 \%)$ & 0.664 \\
\hline Assessed METS & $7.8 \pm 2.1$ & $8.1 \pm 2.4$ & $7.5 \pm 1.7$ & 0.050 \\
\hline Ejection fraction & $0.62 \pm 0.09$ & $0.64 \pm 0.06$ & $0.56 \pm 0.09$ & 0.004 \\
\hline LV mass index & $102.1 \pm 37.7$ & $94.4 \pm 29.6$ & $119 \pm 47.2$ & $<0.001$ \\
\hline Aorta, cm & $3.1 \pm 0.4$ & $3.0 \pm 0.4$ & $3.4 \pm 0.4$ & 0.573 \\
\hline Body surface & $1.7 \pm 0.2$ & $1.7 \pm 0.2$ & $1.7 \pm 0.3$ & 0.073 \\
\hline LV relative thickness & $31.3 \pm 5$ & $32.1 \pm 4.8$ & $29.4 \pm 4.9$ & 0.994 \\
\hline LV WMSI at rest & $1.1 \pm 0.3$ & $1 \pm 0$ & $1.3 \pm 0.4$ & $<0.001$ \\
\hline LV WMSI after exercise & $1.1 \pm 0.3$ & $1 \pm 0$ & $1.4 \pm 0.4$ & $<0.001$ \\
\hline
\end{tabular}

ESE - exercise stress echocardiography; SBP - systolic blood pressure; DBP - diastolic blood pressure; $\mathrm{HR}$ - heart rate; $\mathrm{Cl}$ - chronotropic incompetence; METS metabolic equivalents ; LV - left ventricle; WMSI - wall motion score index.

Table 3 - Univariate analysis of factors that predict mortality and cardiac events

\begin{tabular}{|c|c|c|c|c|c|c|}
\hline & \multicolumn{3}{|c|}{ Total mortality } & \multicolumn{3}{|c|}{ Cardiac events } \\
\hline & RR & $95 \% \mathrm{Cl}$ & $\mathrm{p}$ & $\mathbf{R R}$ & $95 \% \mathrm{Cl}$ & $p$ \\
\hline Male sex & 2.01 & $0.5-7.5$ & 0.294 & 1.18 & $0.3-4.4$ & 0.805 \\
\hline Age & 1.81 & $1.2-2.7$ & 0.003 & 1.27 & $0.9-1.7$ & 0.129 \\
\hline Diabetes mellitus & 1.74 & $0.3-8.4$ & 0.492 & 3.0 & $0.7-12.3$ & 0.122 \\
\hline Obesity & 1.87 & $0.5-7.5$ & 0.378 & 0.39 & $0.5-3.1$ & 0.370 \\
\hline Hypertension & 2.37 & $0.5-11.4$ & 0.282 & 0.68 & $0.2-2.6$ & 0.572 \\
\hline Dyslipidemia & 1.13 & $0.2-5.0$ & 0.874 & 0.68 & $0.2-2.7$ & 0.587 \\
\hline $\mathrm{FH}$ of CAD & 0.51 & $0.1-2.0$ & 0.330 & 0.79 & $0.2-3.0$ & 0.727 \\
\hline Previous CAD & 4.96 & $1.2-19.6$ & 0.023 & 1.01 & $0.2-5.6$ & 0.987 \\
\hline Peak hypertension & 1.05 & $0.1-8.5$ & 0.964 & 0.97 & $0.1-7.8$ & 0.975 \\
\hline $\mathrm{Cl}$ & 2.75 & $0.7-11.0$ & 0.156 & 2.18 & $0.6-8.2$ & 0.250 \\
\hline Ejection fraction & 0.31 & $0.8-1.2$ & 0.098 & 1.42 & $0.2-11.7$ & 0.742 \\
\hline LV relative thickness & 0.36 & $0.7-1.8$ & 0.217 & 0.77 & $0.2-3.3$ & 0.728 \\
\hline ESE result & 2.43 & $0.7-9.1$ & 0.186 & 6.51 & $1.3-31.9$ & 0.021 \\
\hline Ischemia at ESE & 0.77 & $0.1-6.4$ & 0.810 & 7.84 & $1.7-31.2$ & 0.008 \\
\hline Arrhythmia & 2.26 & $0.6-8.4$ & 0.226 & 0.73 & $0.2-3.0$ & 0.662 \\
\hline
\end{tabular}

$\mathrm{FH}$ - family history; $C A D$ - coronary artery disease; $\mathrm{Cl}$ - chronotropic incompetence; $\mathrm{LV}$ - left ventricle; $E S E$ - exercise stress echocardiography. 


\section{Original Article}

\section{Predictors of events}

Cardiac events were predicted by both the result of the $\mathrm{ESE}(\mathrm{RR}=6.5,95 \% \mathrm{Cl}=1.3$ to $31.9, \mathrm{p}=0.021)$ and by the presence of ischemia at the $\mathrm{ESE}(\mathrm{RR}=7.8,95 \% \mathrm{Cl}=1.7$ to $31.2, \mathrm{p}=0.008)$. The mortality predictors were age $(\mathrm{RR}=$ $1.8,95 \% \mathrm{Cl}=1.2$ to $2.7, \mathrm{p}=0.003$ ) and previous CAD (RR $=4.9,95 \% \mathrm{Cl}=1.2$ to $19.6, \mathrm{p}=0.023)$. The ESE result was not a predictor of overall mortality (Table 3 ).

\section{Discussion}

The exercise stress echocardiography is not usually used in patients with LBBB, probably due to the lack of studies in the literature to support this indication. This is the first investigation with such objective in a Brazilian population. The main finding of this research is to demonstrate that patients with LBBB and positive ESE have increased risk for cardiac events.

The prognostic value of the exercise stress echocardiography (ESE), which also includes the tests using pharmacologic stress, has already been established in many other specific groups of individuals, such as in patients with hypertension, diabetes mellitus, left ventricular overload (LVO) and atrial fibrillation ${ }^{15}$.

Marwick et $\mathrm{al}^{16}$ demonstrated that the positive result of the ESE is an independent predictor of death from cardiac causes in hypertensive patients with suspected or known CAD. The study by Cortigiani et $\mathrm{al}^{17}$ found similar results. Smart et $\mathrm{al}^{18}$, in a study of 345 patients with LVO, showed that ESE-induced ischemia was a predictor of events in this group of patients. The ESE also showed a significant prognostic value for late cardiac events in patients with atrial fibrillation, as demonstrated in the study by Poldermans et $\mathrm{al}^{19}$. A study by Oliveira et $\mathrm{al}^{20}$, with the objective to evaluate the prognostic value of ESE in patients with diabetes, showed that those with normal ESE had low rates of cardiac events in the first year after the examination.

The exercise test is the most widely used noninvasive method for diagnosis and risk stratification of CAD, but it is considered inconclusive in patients with $\mathrm{LBBB}^{21,22}$. As there are scarce data regarding the diagnostic potential of exercise stress echocardiography in patients with LBBB, this modality is not recommended by the guidelines of the American College of Cardiology and the American Heart Association, which indicate the use of myocardial scintigraphy on coronary vasodilator and pharmacological stress echocardiography with dobutamine ${ }^{23}$. The alleged limitation of ESE in patients with LBBB is the analysis of septal motility, which may not have good accuracy; in spite of that, the worsening in the septal wall thickening during the ESE is a good marker of ischemia ${ }^{24}$. The study by Peteiro et $\mathrm{al}^{25}$ demonstrated that the ESE has a good

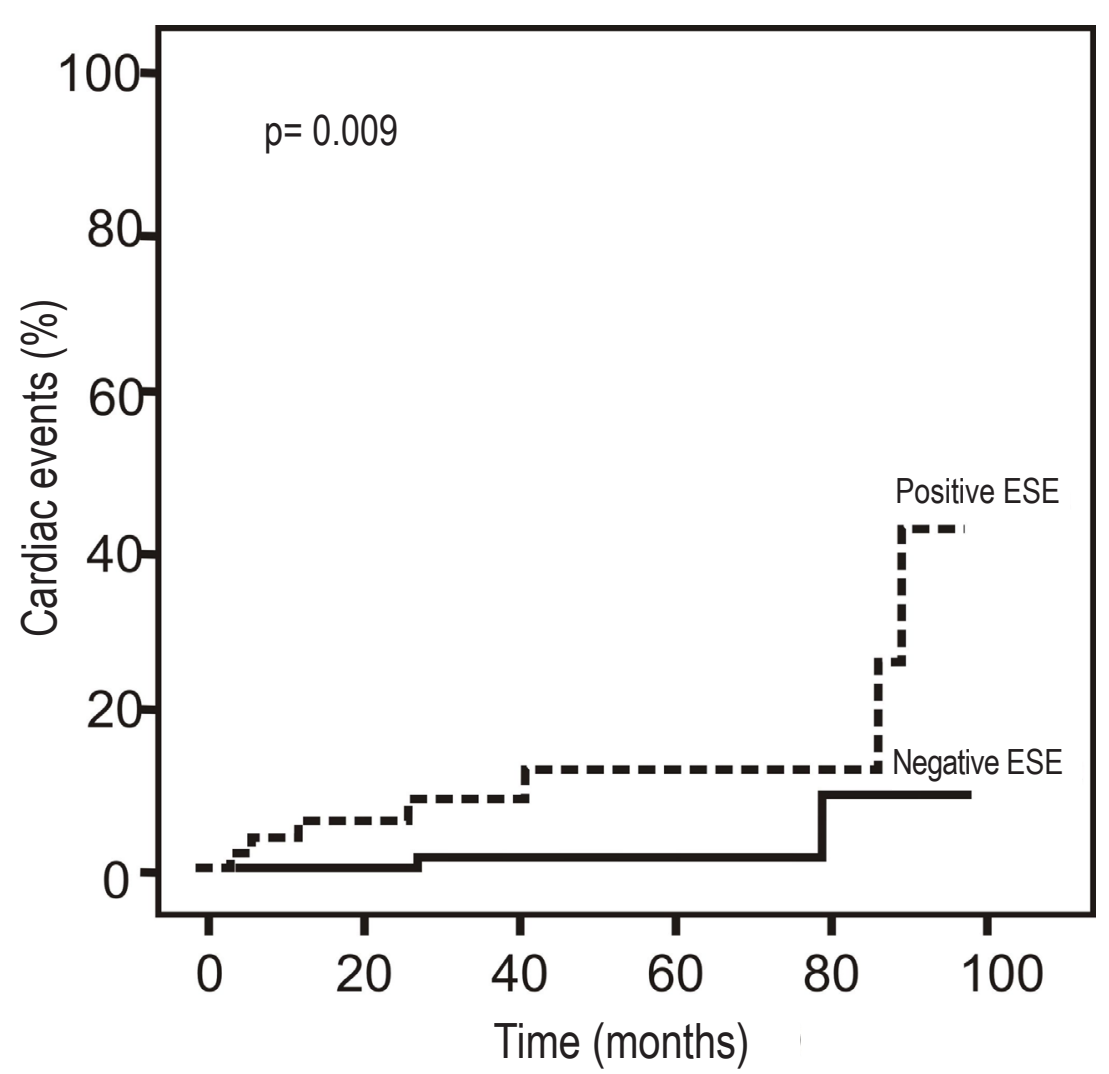

Figure 2 - Kaplan-Meier curve showing the cumulative incidence of cardiac events in LBBB patients with positive and negative ESE. 
effectiveness in patients with LBBB. A study of 35 patients with LBBB undergoing ESE showed a sensitivity of $76 \%$, specificity of $83 \%$ and accuracy of $80 \%$.

Recent articles have demonstrated that the ESE in patients with LBBB may be useful to detect CAD and predict cardiac events in this population. A meta-analysis considering non-invasive tests in patients with LBBB showed that the ESE accuracy to detect CAD was comparable to that of myocardial scintigraphy. The prognostic value for major cardiac events also showed similar results between the ESE and myocardial scintigraphy, which supports the use of these two techniques for the diagnosis and prognosis of patients with $\mathrm{LBBB}$ and suspected $\mathrm{CAD}^{26}$. The American Society of Echocardiography, in its last recommendation, indicated the ESE as an excellent test to measure prognosis in this group ${ }^{15}$.

In the present study, the rate of cardiac events (CABG, PA, AMI and death from cardiac causes) over five years was $15.1 \%$ for the group with a positive test and $1.6 \%$ in the group with a negative test $(p=0.009)$.

This result is similar to that found by Bouzas-Mosquera et $\mathrm{al}^{27}$, who studied 618 patients with LBBB and showed

\section{References}

1. Edmands RE. An epidemiological assessment of bundle-branch block. Circulation. 1966;34(6):1081-7.

2. Rodstein M, Gubner R, Mills JP, Lovell JF, Ungerleider HE. A mortality study in bundle branch block. AMA Arch Intern Med. 1951;87(5):663-8.

3. Hiss RG, Lamb LE. Electrocardiographic findings in 122,043 individuals. Circulation. 1962;25:947-61.

4. Hardarson T, Arnason A, Elíasson GJ, Pálsson K, Eyjólfsson K, Sigfússon N. Left bundle branch block: prevalence, incidence, follow-up and outcome. Eur Heart J. 1987;8(10):1075-9

5. Rotman M, Triebwasser JH. A clinical and follow-up study of right and left bundle branch block. Circulation. 1975;51(3):477-84

6. Baldasseroni S, Opasich C, Gorini M, Lucci D, Marchionni N, Marini M, e cols. Left bundle-branch block is associated with increased 1-year sudden and total mortality rate in 5517 outpatients with congestive heartfailure: a report from the Italian network on congestive heart failure. Am HeartJ. 2002;143(3):398-405.

7. Zannad F, Huvelle E, Dickstein K, van Veldhuisen DJ, Stellbrink C, Køber L, et al. Left bundle branch block as a risk factor for progression to heart failure. Eur J Heart Fail. 2007;9(1):7-14.

8. Elhendy A, Arruda AM, Mahoney DW, Pellikka PA. Prognostic stratification of diabetic patients by exercise echocardiography. J Am Coll Cardiol. 2001;37(6):1551-7.

9. Yao SS, Qureshi E, Syed A, Chaudhry FA. Novel stress echocardiographic model incorporating the extent and severity of wall motion abnormality for risk stratification and prognosis. Am J Cardiol. 2004;94(6):715-9.

10. Arruda-Oslon AM, Juracan EM, Mahoney DW, McCully RB, Roger VL, Pellikka PA. Prognostic value of exercise echocardiography in 5,798 patients: is there a gender difference? J Am Coll Cardiol. 2002;39(4):625-31.

11. Marwick TH. Stress echocardiography. Heart. 2003;89(1):113-8.

12. Armstrong WF, Pellikka PA, Ryan T, Crouse L, Zoghbi WA. Stress echocardiography: recommendations for performance and interpretation of stress echocardiography. Stress Echocardiography Task Force of the a rate of $18 \%$ in the group with positive ESE and $4.6 \%$ in the group with negative ESE $(p<0.001)$. These data demonstrate that even patients with LBBB and positive ESE are more likely to develop cardiac events than those who had a negative test.

Regarding the outcome of death from all causes, unlike Bouzas-Mosquera et $\mathrm{al}^{27}$ who found a rate of $24.6 \%$ in patients with positive ESE and $12.6 \%$ in patients with negative ESE $(p<0.001)$, in the present study we found no significance in the comparison of mortality from all causes at five years $(16.1 \%$ vs. $2.5 \%, p=0.171)$. This finding may reflect the limitations regarding the power of this study (due to the limited number of patients) and not a homogenous evolution of the two groups with regard to overall mortality.

\section{Conclusions}

The exercise stress echocardiography showed to be a predictor of cardiac events (myocardial infarction, percutaneous angioplasty, CABG, and death from cardiac causes) in patients with LBBB.

Nomenclature and Standards Committee of the American Society of Echocardiography. J Am Soc Echocardiogr. 1998;11(1):97-104.

13. Oliveira JLM, Góes TJS, Santana TA, Travassos TF, Teles LD, AnjosAndrade FD, et al. Chronotropic incompetence and a higher frequency of myocardial ischemia in exercise echocardiography. Cardiovasc Ultrasound. 2007;5:38.

14. Armstrong WF, Zoghbi WA. Stress echocardiography: current methodology and clinical applications. J Am Coll Cardiol. 2005;45(11):1739-47.

15. Pellikka PA, Nagueh SF, Elhendy AA, Kuehl CA, Sawada SG. American Society of Echocardiography recommendations for performance, interpretation, and application of stress echocardiography. J Am Soc Echocardiogr. 2007;20(9):1021-41.

16. Marwick T, Case C, Sawada S, Vasey C, Thomas J. Prediction of outcomes in hypertensive patients with suspected coronary disease. Hypertension. $2002 ; 39(6): 1113-8$

17. Cortigiani L, Coletta C, Bigi R. Clinical, exercise electrocardiographic, and pharmacologic stress echocardiographic findings for risk stratification of hypertensive patients with chest pain. Am J Cardiol. 2003;91(8):941-5.

18. Smart S, Dionisopoulos P, Knickelbine T. Dobutamineatropine stress echocardiography for risk stratification in patients with chronic left ventricular dysfunction. J Am Coll Cardiol. 1999;33(2):512-21.

19. Poldermans D, Bax J, Elhendy A, Sozzi F, Boersma E, Thomson I, et al. Long-term prognostic value of dobutamine stress echocardiography in patients with atrial fibrillation. Chest. $2001 ; 119(1): 144-9$.

20. Oliveira JL, Barreto-Filho JA, Oliveira CR, Santana TA, Anjos-Andrade FD, Alves EO, et al. Prognostic value of exercise echocardiography in diabetic patients. Cardiovasc Ultrasound. 2009;7:24.

21. Sicari R, Nihoyannopoulos P, Evangelista A, Kasprzak J, Lancellott $\mathrm{P}$, Poldermans D, et al. Stress echocardiography expert consensus statement: European Association of Echocardiography (EAE) (a registered branch of the ESC). Eur J Echocardiogr. 2008;9(4): 415-37. 


\section{Original Article}

22. Orzan F, Garcia E, Mathur VS, Hall RJ. Is the treadmill exercise test useful for evaluating coronary artery disease in patients with complete bundle branch block? Am J Cardiol. 1978;42(1):36-40.

23. Fleisher LA, Beckman JA, Brown KA, Calkins H, Chaikof E, Fleischmann $\mathrm{KE}$, et al. ACC/AHA 2007 guidelines on perioperative cardiovascular evaluation and care for noncardiac surgery: executive summary: a report of the American College of Cardiology/American Heart Association Task Force on Practice Guidelines. Anesth Analg. 2008;106(3):685-712.

24. Geleijnse ML, Vigna C, KasprzakJD, Rambaldi R, Salvatori MP, Elhendy A, etal. Usefulness and limitations of dobutamine-atropine stress echocardiography for the diagnosis of coronary artery disease in patients with left bundle branch block: a multicentre study. Eur Heart J. 2000;21(20):1666-73.
25. Peteiro J, Monserrat L, Martinez D, Castro-Beiras A. Accuracy of exercise echocardiography to detect coronary artery disease in left bundle branch block unassociated with either acute or healed myocardial infarction. Am J Cardiol. 2000;85(7):890-3, A9.

26. Biagini E, Shaw LJ, Poldermans D, Schinkel AF, Rizzello V, Elhendy A, et al. Accuracy of non-invasive techniques for diagnosis of coronary artery disease and prediction of cardiac events in patients with left bundle branch block: a meta-analysis. Eur J Nucl Med Mol Imaging. 2006;33(12):144251.

27. Bouzas-Mosquera A, Peteiro J, Alvarez-García N, Broullón FJ, GarcíaBueno L, Ferro L, et al. Prognostic value of exercise echocardiography in patients with left bundle branch block. JACC Cardiovasc Imaging. $2009 ; 2(3): 251-9$. 